\title{
Enhancing the reactivity of 1,2-diphospholes in cycloaddition reactions
}

\author{
Almaz Zagidullin`§, Vasili Miluykov, Elena Oshchepkova, Artem Tufatullin, Olga Kataeva \\ and Oleg Sinyashin
}

\author{
Full Research Paper \\ Address: \\ A. E. Arbuzov Institute of Organic and Physical Chemistry, Kazan \\ Scientific Centre, Russian Academy of Sciences, Arbuzov Str. 8, \\ 420088 Kazan, Russia \\ Email: \\ Almaz Zagidullin* - zagidullin@iopc.ru \\ * Corresponding author \\ $\S$ Phone +7-843-273-93-44 \\ Keywords: \\ cycloaddition; phospholes; phosphorus heterocycles; polycyclic \\ phosphines; retro-Diels-Alder reaction
}

Beilstein J. Org. Chem. 2015, 11, 169-173. doi:10.3762/bjoc. 11.17

Received: 22 October 2014

Accepted: 09 January 2015

Published: 27 January 2015

Associate Editor: J. P. Wolfe

(C) 2015 Zagidullin et al; licensee Beilstein-Institut. License and terms: see end of document.

\begin{abstract}
Two different approaches have been employed to enhance the reactivity of 1-alkyl-1,2-diphospholes - the introduction of electronwithdrawing groups either at the phosphorus atoms or in the para-position of the arene ring. The alkylation of sodium 1,2diphospha-3,4,5-triphenylcyclopentadienide with alkyl halides $\mathrm{Hal}_{-} \mathrm{CH}_{2}-\mathrm{R}\left(\mathrm{R}=\mathrm{CN}\right.$, COOEt, $\left.\mathrm{OMe}, \mathrm{CH}_{2} \mathrm{OEt}\right)$ results in corresponding 1-alkyl-3,4,5-triphenyl-1,2-diphospholes (alkyl = $\mathrm{CH}_{2} \mathrm{CN}(\mathbf{1 a}), \mathrm{CH}_{2} \mathrm{COOEt}(\mathbf{1 b}), \mathrm{CH}_{2} \mathrm{OMe}(\mathbf{1 c})$, and $\left(\mathrm{CH}_{2}\right)_{2} \mathrm{OEt}(\mathbf{1 d})$ ), which spontaneously undergo the intermolecular [4+2] cycloaddition reactions at room temperature to form the mixture of the cycloadducts, 2a-c, respectively. However the alkylation of sodium 1,2-diphospha-3,4,5-tri( $p$-fluorophenyl)cyclopentadienide with ethyl iodide leads to stable 1-ethyl-3,4,5-tris( $p$-fluorophenyl)-1,2-diphosphole (1e), which forms the [4 +2$]$ cycloadduct 2,3,4,4a,5,6-hexa( $p$-fluorophenyl)-1-ethyl-1,7,7a-triphospha-4,7-(ethylphosphinidene)indene (2e) only upon heating up to $60{ }^{\circ} \mathrm{C}$. With further heating to $120^{\circ} \mathrm{C}$ with $N$-phenylmaleimide, the cycloadducts $\mathbf{2 a}-\mathbf{c}$ and $\mathbf{2 e}$ undergo the retro-Diels-Alder reaction and form only one product of the $[4+2]$ cycloaddition reaction $\mathbf{3 a}-\mathbf{c}, \mathbf{3 e}$ with good yields up to $65 \%$.
\end{abstract}

\section{Introduction}

Phospholes are weakly aromatic heterocycles and demonstrate rather different properties from those of their S, N and O counterparts $[1,2]$. Due to low their aromaticity, phospholes are of significant interest for the preparation of highly effective catalysts, materials for light-emitting diodes and nonlinear optics $[3,4]$. In contrast to furans, thiophenes and pyrroles, phospholes display cycloaddition and complexation reactions and can be used as starting materials for caged phosphines, phosphinidenes, etc. [2]. At the same time, the presence of electron-withdrawing substituents (cyano-, alkoxy-, or halo-) at the phosphorus atom reduces the aromaticity of the monophosphole ring and facilitates cycloaddition reactions resulting in novel 7-phosphanorbornenes $[5,6]$, which was verified by theoretical calculations and experimental work $[7,8]$. 
At the same time both the presence of the $\mathrm{P}=\mathrm{C}$ bond in phospholes as well as the transient $2 \mathrm{H}$-phospholes [3] increase the cycloaddition reactivity. It was previously demonstrated that 1-alkyl-1,2-diphospholes combine the properties of both $1 H$-phospholes (with thermal stability up to $190{ }^{\circ} \mathrm{C}$ ) and $2 \mathrm{H}$-phospholes (exhibiting high reactivity in the cycloaddition reaction at $25{ }^{\circ} \mathrm{C}$ ) [9-11]. In the present work, attempts to increase the reactivity of the dienic system of 1,2-diphospholes using two different approaches are described: (a) by the introduction of electron-withdrawing groups (EWGs) at the phosphorus atom or (b) the introduction of EWGs to the carbon atoms of aryl substituents. This work will provide access to new polycyclic, organophosphorus compounds having significant potential as weak, bulky ligands in homogeneous catalysis [1214].

\section{Results and Discussion}

The 1-alkyl-1,2-diphospholes 1a-e, incorporating EWGs at the phosphorus atom or in aromatic fragments, are easily accessible by the alkylation of sodium 1,2-diphospha-3,4,5-triarylcyclopentadienide with alkyl halides. The reactions were carried out in THF at $-80{ }^{\circ} \mathrm{C}$ with yields of $55-60 \%$ for $\mathbf{1 a}-\mathbf{e}$ (Scheme 1).

The structures of the obtained compounds, 1a-e, were unambiguously confirmed by ${ }^{31} \mathrm{P},{ }^{1} \mathrm{H}$ and ${ }^{13} \mathrm{C}$ NMR spectroscopy. The ${ }^{31} \mathrm{P}$ NMR spectra of 1a-e (Table 1) showed two doublets in the range of 30-60 and 210-225 ppm, corresponding to threeand two-coordinated phosphorus atoms, respectively, with a large coupling constant ${ }^{1} J_{\mathrm{PP}} \approx 365-410 \mathrm{~Hz}$, which is typical for 1-alkyl-1,2-diphospholes [15].

Remarkably, the coupling constants ${ }^{1} J_{\mathrm{PP}}$ increase with the decrease of the electron-withdrawing properties of the substitutents in the diphosphole ring $\left(\mathrm{CN}>\mathrm{COOEt}>\mathrm{OMe}>\mathrm{CH}_{2} \mathrm{OEt}\right)$ in the series 1a-1d.

\begin{tabular}{|c|c|c|c|c|c|}
\hline & $\delta_{p}, p p m$ & $\Delta \delta_{\mathrm{p}}, \mathrm{ppm}$ & ${ }^{1} J_{\mathrm{PP}}, \mathrm{Hz}$ & $\mathrm{R}$ & $x$ \\
\hline $1 a$ & $\begin{array}{l}225.7\left(P_{1}=C\right) \\
\text { and } 30.8\left(P_{2}\right)\end{array}$ & 194.9 & 363.1 & $\mathrm{CN}$ & $\mathrm{H}$ \\
\hline $1 b$ & $\begin{array}{l}223.3\left(\mathrm{P}_{1}=\mathrm{C}\right) \\
\text { and } 40.5\left(\mathrm{P}_{2}\right)\end{array}$ & 182.8 & 389.0 & COOEt & $\mathrm{H}$ \\
\hline $1 c$ & $\begin{array}{l}209.3\left(P_{1}=C\right) \\
\text { and } 61.2\left(P_{2}\right)\end{array}$ & 148.1 & 404.0 & OMe & $\mathrm{H}$ \\
\hline $1 d$ & $\begin{array}{l}214.1\left(\mathrm{P}_{1}=\mathrm{C}\right) \\
\text { and } 51.9\left(\mathrm{P}_{2}\right)\end{array}$ & 162.2 & 407.3 & $\mathrm{CH}_{2} \mathrm{OEt}$ & $\mathrm{H}$ \\
\hline $1 e$ & $\begin{array}{l}218.5\left(\mathrm{P}_{1}=\mathrm{C}\right) \\
\text { and } 73.4\left(\mathrm{P}_{2}\right)\end{array}$ & 145.1 & 407.8 & $\mathrm{Me}$ & $F$ \\
\hline
\end{tabular}

A large phosphorus-phosphorus coupling constant, ${ }^{1} J_{\mathrm{PP}}$, usually indicates significant $\sigma-\pi$ delocalization of the lone pair of the tricoordinated phosphorus atom into the diphosphole ring system. Thus, the ${ }^{1} J_{\mathrm{PP}}$ coupling constant for a non-aromatic 1,2-diphosphacyclopentene is observed at around $220 \mathrm{~Hz}$ [16], although both phosphorus atoms of the highly aromatic 1-(2,4,6-tri-tert-butylphenyl)-1H-1,2-diphosphole are coupled with a larger phosphorus-phosphorus constant $\left({ }^{1} J_{\mathrm{PP}}=\right.$ $528.2 \mathrm{~Hz}$ ) [17]. The same phenomena was noted for the 1,2,4triphosphole with the planar tricoordinated phosphorus [18]. Thus, the increase of ${ }^{1} J_{\mathrm{PP}}$ in a sequence from $1 \mathrm{a}$ to $1 \mathbf{d}$ could imply the increasing delocalization of the RP-fragment within the diphosphole system that reflects the stability and the reactivity of 1,2-diphosphole.

Indeed, the compounds $\mathbf{1 a}, \mathbf{b}$ are stable only at temperatures below $+5{ }^{\circ} \mathrm{C}$, while $1 \mathrm{c}$ is stable at room temperature for a few hours. 1,2-Diphosphole $\mathbf{1 d}$ is more stable and no cycloaddition was observed upon heating in toluene. Upon standing, the diphospholes 1a-c undergo spontaneous [4+2] cycloaddition reactions leading to a mixture of cycloadducts (Scheme 2 ). The ${ }^{31} \mathrm{P}$ NMR spectra of the reaction mixtures showed many multi-

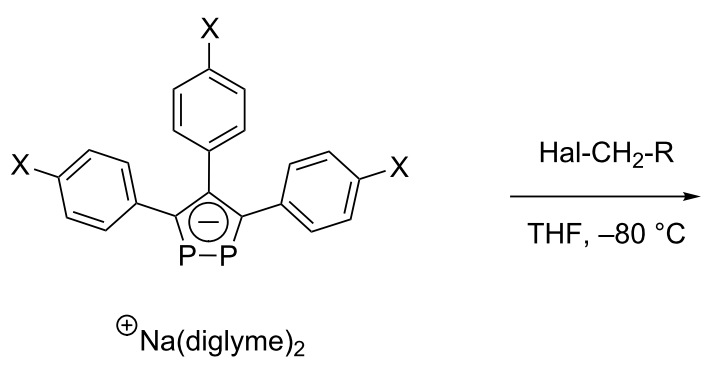<smiles>[R]Cp1pc(-c2ccc([X])cc2)c(-c2ccc([X])cc2)c1-c1ccc([X])cc1</smiles>

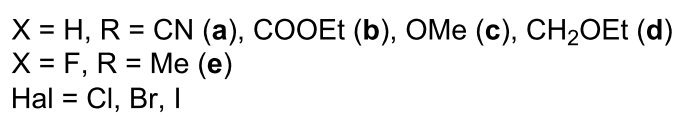


plets at 80 and $-40 \mathrm{ppm}$ with a coupling constant ${ }^{1} J_{\mathrm{PP}}$ ca. $200-210 \mathrm{~Hz}$ characteristic for the products of [4+2] cycloaddition reaction - 1,7-diphosphanorbornadienes [9,11]. Remarkably, 1-alkyl-1,2-diphospholes without EWGs reveal significant thermal stability and dimerization was observed only upon heating to $190{ }^{\circ} \mathrm{C}$ leading to the product of the $[2+2]$ cycloaddition reaction [9]. At the same time, 3,4,5-tri( $p$-fluorophenyl)-1-ethyl-1,2-diphosphole (1e) is stable at room temperature and undergoes the $[4+2]$ cycloaddition reaction only upon heating at $60{ }^{\circ} \mathrm{C}$ resulting in only one product, $2 \mathrm{e}$ (Scheme 2).

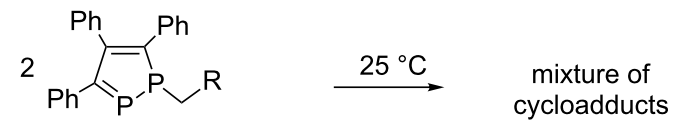

$$
\begin{aligned}
& \mathrm{R}=\mathrm{CN} \text {, COOEt, OMe } \\
& \text { 1a-c } \\
& \text { 2a-c }
\end{aligned}
$$

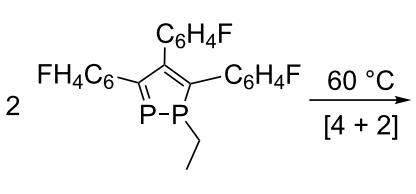

$1 e$

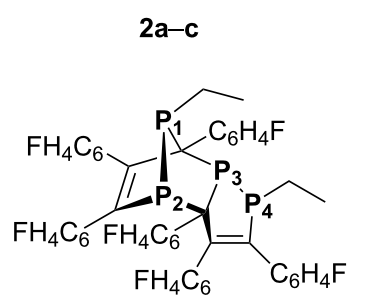

$2 e$
Scheme 2: The cycloaddition reactions of 1-alkyl-1,2-diphospholes 1a-e.

The molecular structure of $2 \mathrm{e}$ (Figure 1) was verified by X-ray crystallography. The crystal structure analysis of $2 \mathbf{e}$ showed that only the endo isomer was formed with the alkyl group in antiorientation with respect to the double bond of the ring.

In the case of $\mathbf{2 a}-\mathbf{c}$, it would be assumed that similar [4 +2$]$ cycloadducts are formed according to the range of signals in the ${ }^{31} \mathrm{P}$ NMR spectra. However, in this case, several stereoisomers are formed due to the high reactivity of the 1,2-diphospholes containing EWGs on the phosphorus atom. It should be noted that this is the first example of [4+2] cycloaddition between two diphosphole molecules where 1,2-diphosphole acts as a diene and a dienophile in one reaction. Therefore, these isomeric cycloadducts, $\mathbf{2 a - c}$, can be a source of reactive 1,2-diphospholes containing EWGs 1a-c in the retro-Diels-Alder reaction [19].

Indeed, upon further heating up to $120{ }^{\circ} \mathrm{C}$, the mixture of the cycloadducts $\mathbf{2 a}-\mathbf{c}$ as well the cycloadduct $\mathbf{2 e}$ underwent the retro-Diels-Alder reaction to form monomeric 1,2-diphospholes, 1a-c, 1e, which were trapped by $N$-phenylmaleimide to form the compounds 3a-c, 3e with yields of 55-65\% (Scheme 3).

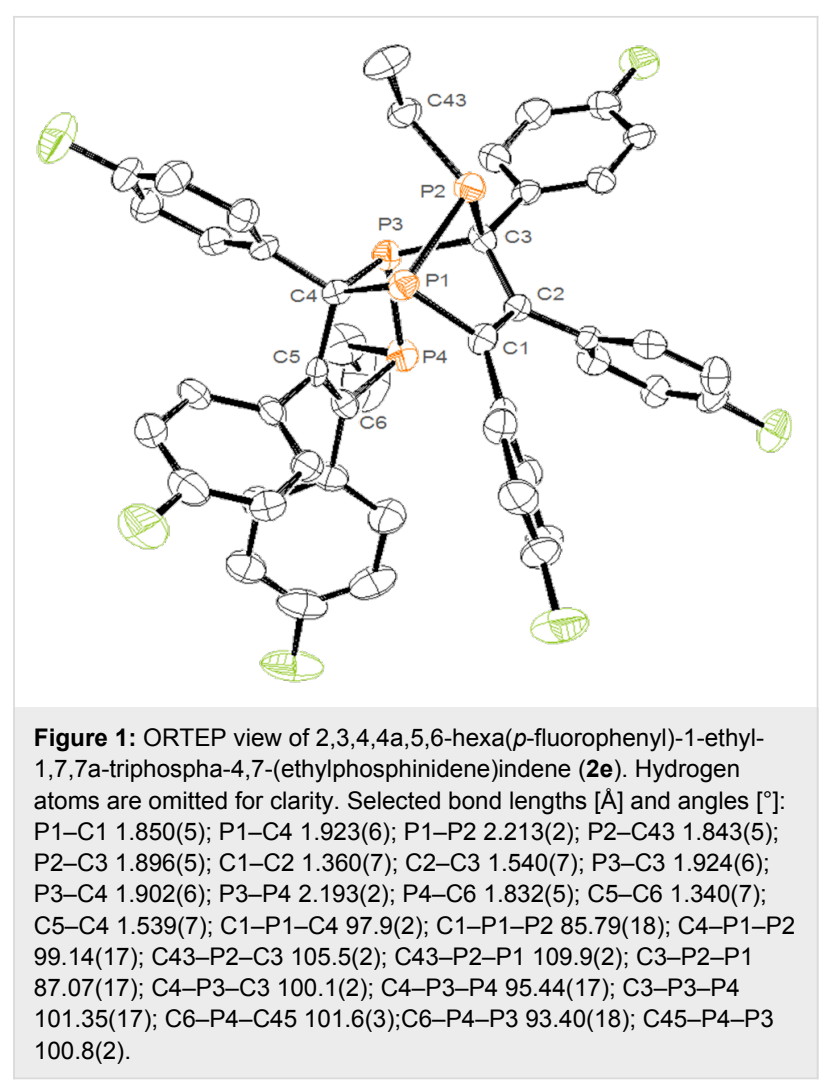

After heating for $25-30$ hours at $120{ }^{\circ} \mathrm{C}$ in toluene, the ${ }^{31} \mathrm{P}$ NMR spectra of the reaction mixture displayed only two doublets at around -25 and $60 \mathrm{ppm}$ with ${ }^{1} J_{\mathrm{PP}}=200 \mathrm{~Hz}$. This indicates the high stereoselectivity of this reaction. The ${ }^{1} \mathrm{H}$ NMR spectra of the reaction mixtures show only two doublets for protons of the $N$-phenylmaleimide fragment in the range of 4.6-4.8 ppm. Based on our previous results [20], we can conclude that only an anti-endo-isomer was formed in each case.

\section{Conclusion}

In summary, we have demonstrated the prospect of increasing the reactivity of 1,2-diphospholes using two different approaches: (a) introduction of EWGs at the phosphorus atom and (b) introduction of EWGs at the carbon atoms of aryl substituents. New 1-alkyl-1,2-diphospholes, 1a-c, 1e, containing EWGs demonstrated high reactivity and underwent intermolecular $[4+2]$ cycloaddition reactions at $25-60{ }^{\circ} \mathrm{C}$ leading to a single product, $\mathbf{2 e}$, or a mixture of $[4+2]$ cycloadducts 2a-c. Additionally, upon further heating up to $120{ }^{\circ} \mathrm{C}$ with $\mathrm{N}$-phenylmaleimide, the mixture of isomeric cycloadducts $\mathbf{2 a}-\mathbf{c}, \mathbf{2 e}$ underwent the retro-Diels-Alder reaction, yielding only one product of $[4+2]$ cycloaddition $\mathbf{3 a}-\mathbf{c}$, and 3e. The same chemical behavior was observed for 1-alkyl1,2-diphosphole-1-oxides, which underwent $[4+2]$ cycloaddition at $25^{\circ} \mathrm{C}$ and the retro-Diels-Alder reaction at $100{ }^{\circ} \mathrm{C}$ [21]. 


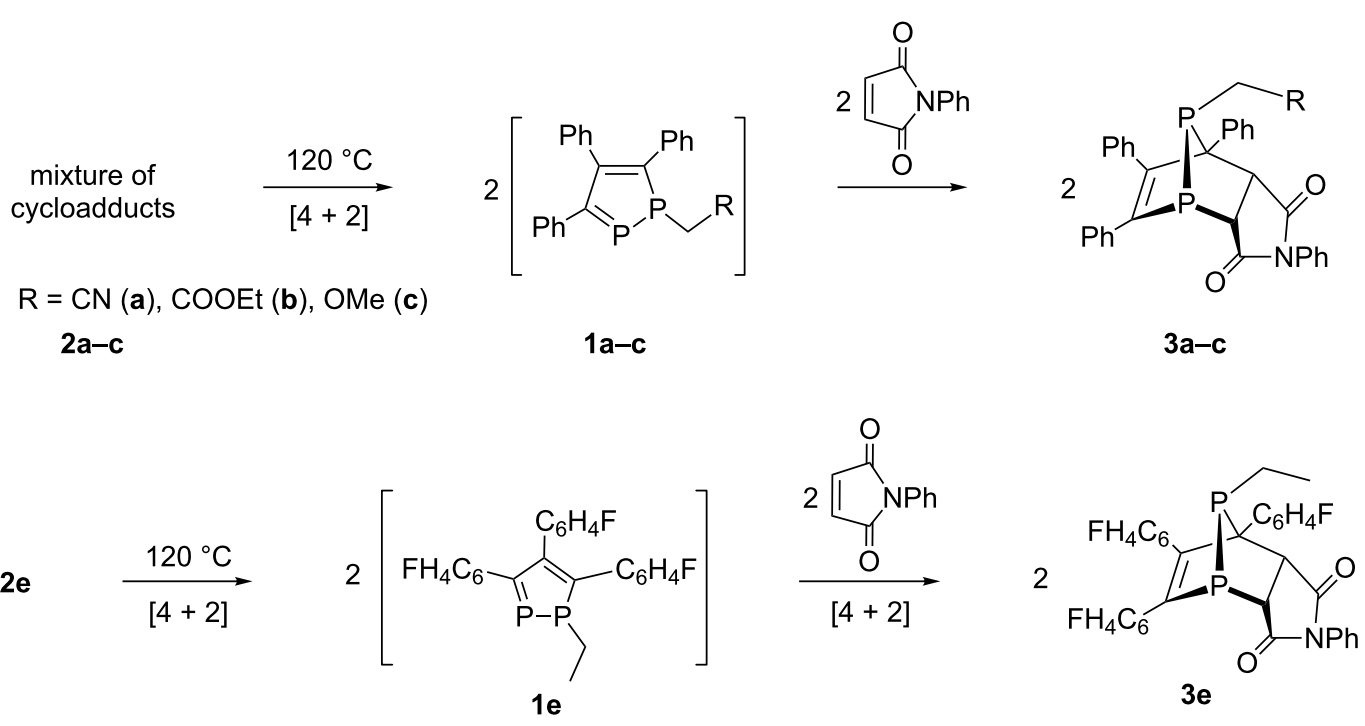

Scheme 3: The retro-Diels-Alder reactions of the cycloadducts $\mathbf{2 a - c}$, and $\mathbf{2 e}$

Compared with 1-alkyl-1,2-diphospholes, the new 1-R-1,2-diphospholes 1a-c, 1e containing EWGs were less stable. Given that they are more reactive in cycloaddition reactions, this work presents the opportunity for new polycyclic phosphines.

\section{Supporting Information}

\section{Supporting Information File 1}

Experimental procedures and characterization data. [http://www.beilstein-journals.org/bjoc/content/ supplementary/1860-5397-11-17-S1.pdf]

\section{Acknowledgements}

This work was supported by the Russian Science Foundation (14-13-00589).

\section{References}

1. von Ragué Schleyer, P.; Maerker, C.; Dransfeld, A.; Jiao, H.; van Eikema Hommes, N. J. R. J. Am. Chem. Soc. 1996, 118, 6317-6318. doi:10.1021/ja960582d

2. Zagidullin, A. A.; Bezkishko, I. A.; Miluykov, V. A.; Sinyashin, O. G. Mendeleev Commun. 2013, 23, 117-130. doi:10.1016/j.mencom.2013.05.001

3. Mathey, F. Acc. Chem. Res. 2004, 37, 954-960. doi:10.1021/ar030118v

4. Quin, L. D. Curr. Org. Chem. 2006, 10, 43-78. doi:10.2174/138527206775192997

5. Mattmann, E.; Mathey, F.; Sevin, A.; Frison, G. J. Org. Chem. 2002, 67, 1208-1213. doi:10.1021/jo0108156

6. Mattmann, E.; Simonutti, D.; Ricard, L.; Mercier, F.; Mathey, F. J. Org. Chem. 2001, 66, 755-758. doi:10.1021/jo001096i
7. Westerhausen, M.; Stein, B.; Ossberger, M.; Görls, H.; Ruiz, J.; Nöth, H.; Mayer, P. ARKIVOC 2007, No. iii, 46-59.

8. Mattmann, E.; Mercier, F.; Ricard, L.; Mathey, F. J. Org. Chem. 2002, 67, 5422-5425. doi:10.1021/jo025713+

9. Miluykov, V.; Bezkishko, I.; Zagidullin, A.; Sinyashin, O.; Lönnecke, P.; Hey-Hawkins, E. Eur. J. Org. Chem. 2009, 1269-1274. doi:10.1002/ejoc.200801181

10. Zagidullin, A. A.; Miluykov, V. A.; Krivolapov, D. B.; Kharlamov, S. V.; Latypov, S. K.; Sinyashin, O. G.; Hey-Hawkins, E. Eur. J. Org. Chem. 2011, 4910-4918. doi:10.1002/ejoc.201100615

11. Zagidullin, A.; Ganushevich, Y.; Miluykov, V.; Sinyashin, O.; Hey-Hawkins, E. Phosphorus, Sulfur Silicon Relat. Elem. 2013, 188, 238-242. doi:10.1080/10426507.2012.744017

12. Robin, F.; Mercier, F.; Ricard, L.; Mathey, F.; Spagnol, M. Chem. - Eur. J. 1997, 3, 1365-1369. doi:10.1002/chem.19970030824

13. Clochard, M.; Mattmann, E.; Mercier, F.; Ricard, L.; Mathey, F. Org. Lett. 2003, 5, 3093-3094. doi:10.1021/ol035067g

14. Germoni, A.; Deschamps, B.; Ricard, L.; Mercier, F.; Mathey, F. J. Organomet. Chem. 2005, 690, 1133-1139. doi:10.1016/j.jorganchem.2004.11.018

15. Milyukov, V. A.; Bezkishko, I. A.; Zagidullin, A. A.; Sinyashin, O. G.; Hey-Hawkins, E. Russ. Chem. Bull. 2010, 59, 1232-1236. doi:10.1007/s11172-010-0226-9

16. Doxsee, K. M.; Wood, N. P.; Hanawalt, E. M.; Weakley, T. J. R. Heteroat. Chem. 1996, 7, 383-389. doi:10.1002/(SICI)1098-1071(199610)7:5<383::AID-HC16>3.0.CO;2-M

17. Ionkin, A. S.; Marshall, W. J.; Fish, B. M.; Schiffhauer, M. F.; Davidson, F.; McEwen, C. N.; Keys, D. E. Organometallics 2007, 26, 5050-5058. doi:10.1021/om7005084

18. Cloke, F. G. N.; Hitchcock, P. B.; Hunnable, P.; Nixon, J. F.; Nyulászi, L.; Niecke, E.; Thelen, V. Angew. Chem., Int. Ed. 1998, 37, 1083-1086. doi:10.1002/(SICI)1521-3773(19980504)37:8<1083::AID-ANIE1083>3. $0 . \mathrm{CO} ; 2-\mathrm{C}$

19. Kotha, S.; Banerjee, S. RSC Adv. 2013, 3, 7642-7666. doi:10.1039/c3ra22762f 
20. Zagidullin, A.; Miluykov, V.; Sinyashin, O.; Lönnecke, P.; Hey-Hawkins, E. Heteroat. Chem. 2014, 25, 28-34. doi:10.1002/hc.21132

21. Zagidullin, A.; Ganushevich, Y.; Miluykov, V.; Krivolapov, D.;

Kataeva, O.; Sinyashin, O.; Hey-Hawkins, E. Org. Biomol. Chem. 2012, 10, 5298-5306. doi:10.1039/c2ob25532d

\section{License and Terms}

This is an Open Access article under the terms of the Creative Commons Attribution License

(http://creativecommons.org/licenses/by/2.0), which permits unrestricted use, distribution, and reproduction in any medium, provided the original work is properly cited.

The license is subject to the Beilstein Journal of Organic Chemistry terms and conditions:

(http://www.beilstein-journals.org/bjoc)

The definitive version of this article is the electronic one which can be found at:

doi:10.3762/bjoc.11.17 